\title{
Numerical Study of Impingement Cooling Under Constant Heat Flux
}

$$
\text { Gao Apeng }{ }^{1, a} \text {, Lei Yubing }{ }^{2, b} \text {, Jiang Yang }{ }^{2, c}
$$
${ }^{1}$ Nanjing University of Aeronautics and Astronautics, Jiangsu Province's Key Laboratory of
Aerospace Power System, Nan Jing 210016, China

${ }^{2}$ Nanjing University of Aeronautics and Astronautics, Jiangsu Province's Key Laboratory of Aerospace Power System, Nan Jing 210016, China

a285641583@qq.com, bleiyb@nuaa.edu.cn, ' $1183034087 @ q q . c o m$

Keywords: Impingement cooling, heat flux, rotating detonation engine.

\begin{abstract}
Take the rotating detonation engine combustion chamber wall which under great heat flux as the research background. The characteristics of impingement cooling under different parameters were studied by numerical simulation, then analyzing and getting a better Impingement cooling structure. It is found that under the same air mass flow rate and constant heat flux,when the diameter of impingement hole is $\mathrm{d}=4 \mathrm{~mm}$, the impingement distance is $\mathrm{H}=4 \mathrm{~mm}$, the hole spacing is $\mathrm{Xn}=\mathrm{Yn}=35.168 \mathrm{~mm}$, the cooling effect is the best. With the cooling structure, the cooling of the heated wall with constant heat flux of $500000 \mathrm{~W} / \mathrm{m}^{2}$ was studied. The results show that when the Reynolds number is $\mathrm{Re}=50000$, the wall is cooled and the wall temperature is reduced to a reasonable range.
\end{abstract}

\section{Introduction}

In the cooling structure of aero-engine combustion chamber, impingement cooling is an efficient cooling method. The impingement cooling can quickly take away the heat accumulated on the wall and improve the heat transfer coefficient of the wall, so it has wide application in aero-engine. Detonation combustion instantaneously release a lot of heat, the results of the literature ${ }^{[2-3]}$ show that the rotating detonation engine combustion chamber wall heat flux is very large. In the literature ${ }^{[4-5]}$, a rotating detonation engine with cooling structure was experimentally studied. It was shown that the combustion chamber wall of rotating detonation engine could be protected by air cooling. Based on the structure and operating environment of rotating detonation engine combustion chamber, the Impingement cooling is adopted to cool the combustion chamber wall. The impingement cooling can impinge on the wall surface at a high jet velocity, and reduce the thickness of the boundary layer of the impact zone and its vicinity, so as to achieve the effect of forced convection heat transfer. In the literature ${ }^{[6-7]}$ which through the experimental method, designing the Jet impact hole test pieces with different geometric parameters . The results show that convection heat transfer coefficient increases with the increase of jet Reynolds number, and convective heat transfer effect is reduce with the increase of impact spacing. Reasonable diameters of impinging hole will help to improve the effect of heat transfer. In the literature ${ }^{[8-12]}$ which use numerical method to study the Impingement cooling, the results shows that the back jet is destroyed by cross flow and lead to the convective heat transfer is complex. Reducing the impact distance and increasing the Reynolds number can increase the convective heat transfer. Although a lot of researches have been done on impingement cooling at home and abroad, the research under the condition of large heat flux wall is not enough. Therefore, the main contents of this paper is (1) Research on the technology of enhancing heat transfer--The characteristics of impingement cooling.(2) Using the better cooling structure which has been obtained to try to cool the walls at large heat flux.

\section{The combustion chamber wall impingement cooling model and the numerical computational method}

The computational model of this paper is shown in Fig.1, The fan-shaped region of the $1 / 4$ circle of the combustion chamber of the rotating detonation engine was simulated. Among them 1 is 
the cold flow inlet, 2 is the impingement plate, 3 is the target plate, 4 is the impingement holes, 5 is the impingement cavity, 6 is the cold flow outlet. Computational model set $\mathrm{Z}$ axis direction as axial, and along the coordinate system $x-y$ plane for circumferential. In the article the adjacent hole spacing which along the circumferential and axial is $\mathrm{Xn}$ and Yn respectively. Fig. 2 is along the axial section, the model is divided into upper and lower layers. The upper part of the impingement plate is the impingement cavity and the lower part is the jet channel. The height of the jet channel is the impingement distance $\mathrm{H}$. The model includes the fluid region and the solid region. The axial length of the model is $75 \mathrm{~mm}$, The radius of the impingement target plate is $50 \mathrm{~mm}$, the thickness of the both plates are all 1mm, 11.124mm distance is left along the axial front and back. In this article the diameter and numbers of impinging hole are varies according to the research parameters.

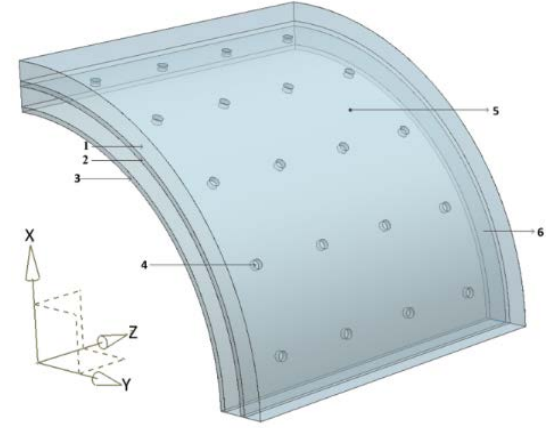

Fig.1 Impingement cooling computational model

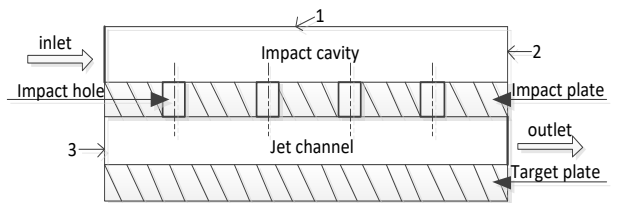

Fig.2 Computational model along the axial section

The numerical simulation uses density-based to solve by using Fluent software. The Transition SST model is adopted for the turbulence model. The discrete parameters of each physical quantity are the second order upwind,the entrance is the mass flow rate inlet, the inlet total temperature of the cooling fluid is $300 \mathrm{~K}$, the outlet is the pressure outlet, the target plate is heated by the constant heat flux, and the model section is set as the periodic boundary condition. As shown in Fig.2, the impingement plate and the target plate are made of stainless steel, and the solid walls 1,2 and 3 are set as the adiabatic walls . Using ANSYS ICEM to divide unstructured grid, Mesh encryption is applied to the impinging jet holes and the impingement target plate which contact with the fluid. At the same time, boundary layer meshes are divided. The total number of grid is about 900000; the mesh is shown in Fig.3.

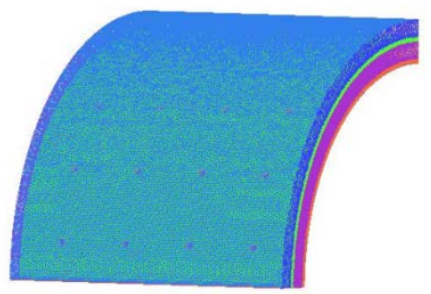

Fig.3 Computational grid of impingement cooling model

$\mathrm{Nu}$ is often used to characterize the cooling effect in impingement cooling. The $\mathrm{Nu}$ is defined as:

$$
N u=\frac{q d}{\left(\mathrm{~T}_{W}-\mathrm{T}_{r e f}\right) \lambda}
$$

Where $\mathrm{q}$ is the heat flux; $\lambda$ is the thermal conductivity of the air; $\mathrm{d}$ is the diameter of the impingement hole; $\mathrm{T}_{\text {ref }}$ is the temperature of the inlet cold flow; And $\mathrm{T}_{\mathrm{W}}$ is temperature of the target plate which contact with the fluid.

The jet Reynolds number Re is defined as:

$$
\operatorname{Re}=\frac{\rho v d}{\mu}
$$

Where $\mu$ is the dynamic viscous coefficient; $\rho$ is the density; and $\mathrm{v}$ is the jet velocity.

The relationship between jet Reynolds number Re and the cold air mass flow is: 


$$
\operatorname{Re}=\frac{4 q_{m}}{\pi d n \mu}
$$

Where is the number of impingement holes; $q_{m}$ is mass flow of the cold flow.

\section{Study and analyze the characteristics of Impingement Cooling}

\section{The influence of impingement hole diameter on $\mathrm{Nu}$.}

The arrangement of impingement holes is shown in Fig.1, selecting different holes are $\mathrm{d}=2 \mathrm{~mm}$, $4 \mathrm{~mm}, 6 \mathrm{~mm}$ and $8 \mathrm{~mm}$ to comparatively study respectively. In the case of different diameters, the mass flow rate is $\mathrm{q}_{\mathrm{m}}=0.016767 \mathrm{~kg} / \mathrm{s}$, the impact distance is $\mathrm{H}=4 \mathrm{~mm}$, the distance between impingement holes is $\mathrm{Xn}=\mathrm{Yn}=17.584 \mathrm{~mm}$, the target plate is provided a constant heat flux is $\mathrm{q}=$ $50000 \mathrm{~W} / \mathrm{m}^{2}$.

Fig. 4 and Fig.5 respectively is the distribution diagram of the $\mathrm{Nu}$ number along the axial direction of the combustion chamber wall and comparison chart of the average Nu number which under different holes diameter. It can be seen from the figures, when the other conditions are certain, $\mathrm{d}=4 \mathrm{~mm}$, along the axis of the value of each point and the average Nu number is relatively large. In this paper, the value of each point along the axial direction is the average value in the circumferential direction. It can be seen from the fig.4, when $d=2 \mathrm{~mm}$ and $\mathrm{d}=4 \mathrm{~mm}$, Nu curve is wavy along the axial direction, but when $\mathrm{d}=6 \mathrm{~mm}$ and $\mathrm{d}=8 \mathrm{~mm}$, Nu curve is similar to a straight line. This is because when the hole diameter is small, the Re of each hole is larger, the impact velocity of the jet is larger, the cooling effect of the impact stagnation area is obvious, the cooling effect between the holes is relatively poor. When the diameter is large, the impact velocity is small and the impingement cooling effect is poor, there is no big difference between the cooling effect of the impact stagnation area and the cooling effect between the holes. The impact cooling effect is the result of the combined action of impact forced heat transfer and cross flow convection heat transfer. It can be seen from Fig. 5 when $d=4 \mathrm{~mm}$ heat transfer the best, followed by $\mathrm{d}=8 \mathrm{~mm}$, and finally $\mathrm{d}$ $=6 \mathrm{~mm}$ and $\mathrm{d}=2 \mathrm{~mm}$. This is because when $\mathrm{d}=4 \mathrm{~mm}$ impact forced heat transfer is dominant , when $d=8 \mathrm{~mm}$, the convection heat transfer is dominant, while at $d=2 \mathrm{~mm}$ the jet velocity is increased. However the stagnation region of the jet impinged on the target surface is lesser, the target plate temperature distribution is not uniform, and the overall cooling effect is poor. When $\mathrm{d}=$ $6 \mathrm{~mm}$ the jet velocity is relatively small, the effect of impingement cooling is weakened, and the stagnation region of the jet is smaller than that of the case of $d=8 \mathrm{~mm}$. At the same time along the axial direction, the jet in the back of the model is impaired as it crosses the cross flow. So the impact cooling structure hole diameter should be reasonable, so as to obtain better cooling effect.

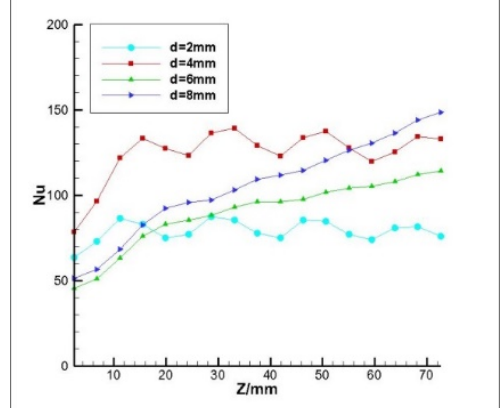

Fig.4 Distribution of Nu along axis under different holes diameters

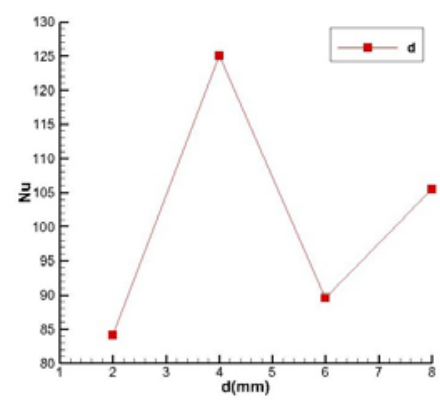

Fig.5 Comparison chart of average $\mathrm{Nu}$ under different holes diameters

\section{The influence of impingement distance on $\mathrm{Nu}$.}

From the Fig. 4 and Fig.5,it can be seen, the average $\mathrm{Nu}$ is the highest when $\mathrm{d}=4 \mathrm{~mm}$, so choose the diameter. The impact distance are $\mathrm{H}=4 \mathrm{~mm}, 8 \mathrm{~mm}, 12 \mathrm{~mm}$ and $16 \mathrm{~mm}$, Other conditions as above. Fig. 6 and Fig.7 respectively is the distribution diagram of the Nu number along the axial direction of the combustion chamber wall and comparison chart of the average Nu number, which under different impingement distance. It can be seen from the Fig.4 and Fig.5, when the boundary 
conditions are the same, Nu shows a significant difference. The $\mathrm{Nu}$ is largest when the impingement distance is $\mathrm{H}=4 \mathrm{~mm}$, which indicates that the impingement distance $\mathrm{H}=4 \mathrm{~mm}$, and wall heat transfer capacity is strong. This is because the impingement distance increases, and the distance between the impingement plate and the target plate increases, and the jet tends to diverge after passing through the impingement hole. The impingement distance increases, the impingement velocity is decrease when fluid reaches the target plate, the efficiency of impingement cooling decreases, and the heat transfer efficiency decreases, and resulting in a decrease of the Nu. This shows that the impingement distance needs to be set reasonable, so as to achieve a good cooling effect.

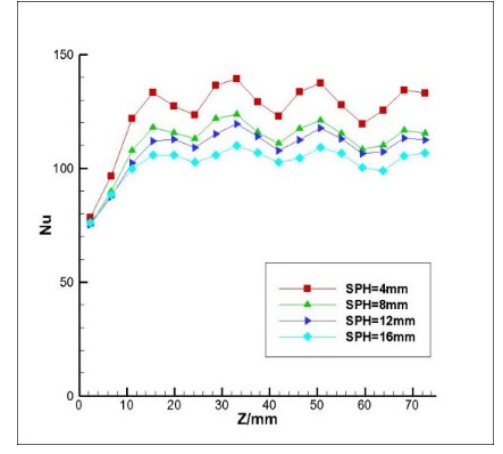

Fig.6 Distribution of Nu along axis under different impingement distance

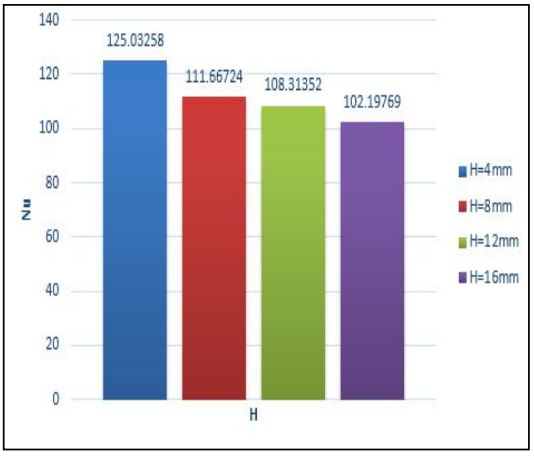

Fig.7 Comparison chart of average $\mathrm{Nu}$ under different impingement distance

\section{The influence of hole spacing on Nu.}

Different hole spacing caused by the number of holes. Under the same mass flow rate, if the number of holes is less, the jet velocity is larger. This article chose the hole spacing respectively are $\mathrm{Xn}=\mathrm{Yn}=5.861333 \mathrm{~mm}, \mathrm{Xn}=\mathrm{Yn}=8.792 \mathrm{~mm}, \mathrm{Xn}=\mathrm{Yn}=17.584 \mathrm{~mm}$ and $\mathrm{Xn}=\mathrm{Yn}=35.168 \mathrm{~mm}$, and the hole diameter $\mathrm{d}=4 \mathrm{~mm}$, the impingement distance $\mathrm{H}=4 \mathrm{~mm}$, the mass flow rate is $\mathrm{q}_{\mathrm{m}}=0.016767 \mathrm{~kg} / \mathrm{s}$. Fig. 8 and Fig. 9 respectively is the distribution diagram of the Nu number along the axial direction of the combustion chamber wall and comparison chart of the average $\mathrm{Nu}$ number, which under different hole spacing. It can be seen from Fig. 8 that the hole spacing is large and the Nu along the axial direction increases accordingly. This shows that the hole spacing increases, the jet velocity increases, and the impact of jet cooling is dominant, so the heat transfer effect is better. While the smaller the hole spacing, the smaller the jet velocity of a single jet hole cannot form an effective jet cooling. In Fig.8, the Nu of the target plate at the entrance is large when the hole spacing is 35.168 $\mathrm{mm}$. This is because the jet is hardly affected by the cross flow at the entrance, and the Nu becomes smaller at the next row of holes. The upstream cross flow causes a loss of the jet velocity, so that the cooling effect is reduced. It can be seen from Fig .9 that the average Nu of the target plate becomes larger as the holes spacing increases. In this paper the research range of parameters, it shows that the cooling effect is better when the hole spacing is $\mathrm{Xn}=\mathrm{Yn}=35.168 \mathrm{~mm}$.

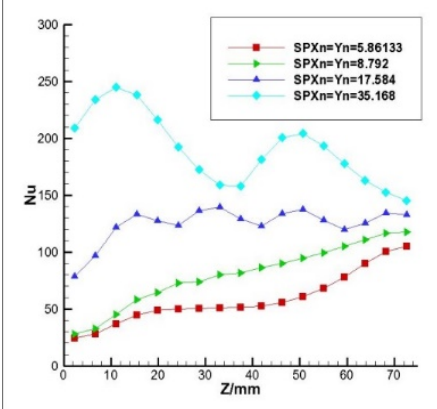

Fig.8 Distribution of Nu along axis under different hole spacing

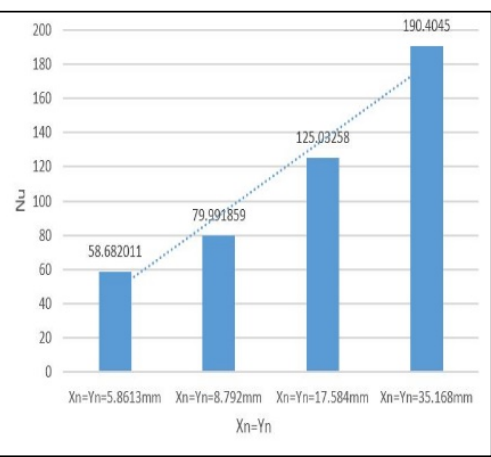

Fig.9 Comparison chart of average $\mathrm{Nu}$ under different hole spacing

The influence of arrangement on Nu.

Fig.10 is the arrangement diagram of aligned and staggered. The number of holes and the diameter are the same, and the hole diameter is $\mathrm{d}=4 \mathrm{~mm}$, the impingement distance is $\mathrm{H}=4 \mathrm{~mm}$, the 
hole spacing is $\mathrm{Xn}=\mathrm{Yn}=17.584 \mathrm{~mm}$. Three types of jet Reynolds numbers were selected, and the corresponding mass flow rates respectively were $\mathrm{q}_{\mathrm{m} 1}=0.0111784 \mathrm{~kg} / \mathrm{s}, \mathrm{q}_{\mathrm{m} 2}=0.0223568 \mathrm{~kg} / \mathrm{s}$ and $\mathrm{q}_{\mathrm{m} 3}$ $=0.0447136 \mathrm{~kg} / \mathrm{s}$. The other conditions are the same. It can be seen from Fig. 11,the Nu curve along the axial direction a wavy shape when the arrangement rder is aligned, but it is similar to a straight line when the arrangement order is staggered. This is because the heat transfer effect in the stagnation zone is better than that between the holes, and the distribution of the impinging cooling jets in the staggered arrangement is more uniform than in the aligned arrangement. Additionally, it is can be seen from the Fig.11,there is no big difference of the $\mathrm{Nu}$ between the different arrangement. It is shown that the arrangement of the holes has little effect on the cooling effect under different impact Reynolds numbers.

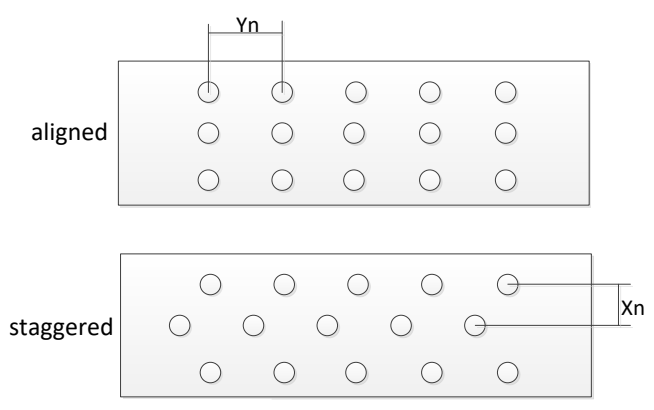

Fig.10 The arrangement diagram of aligned and staggered

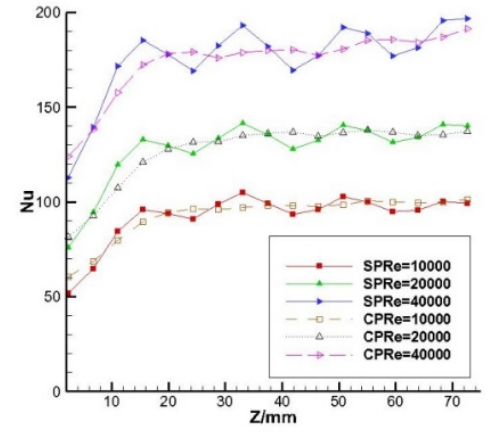

Fig.11 Distribution of Nu along axis under different arrangement

The influence of Reynolds number on $\mathrm{Nu}$.

Fig.12 shows the distribution of average Nu under different Reynolds numbers. The data in the figure correspond to the hole diameter range is $4 \sim 8 \mathrm{~mm}$, hole spacing range is $5.861 \sim 35.168 \mathrm{~mm}$, the cooling air mass flow range is $0.0111784 \sim 0.0447136 \mathrm{~kg} / \mathrm{s}$. It can be seen from the figure, as the Reynolds number of the jet increases, the average $\mathrm{Nu}$ of the target plate shows an increasing tendency. This is because as the jet Reynolds number increases, the velocity of the impinging jet increases, so that the effect of forcing heat transfer is enhanced and the average $\mathrm{Nu}$ of the target plate is increased. When the jet Reynolds number Re is below 20000, the average $\mathrm{Nu}$ of the target plate rises faster, but when the jet Reynolds number continues to increase, the upward trend of the target plate Nu slows down. Because the impinging jet is affected by the cross flow as the Reynolds number increases, the effect of forcing heat transfer is weakened slightly, so the average Nu trend of target plate is slowed down. In the range of parameters studied in this section, the fitting relationship between the jet Reynolds number Re and target plate $\mathrm{Nu}$ can be obtained from the data in Fig.12 that when increasing the Reynolds number Re of jet can improve the heat transfer effect of target plate.

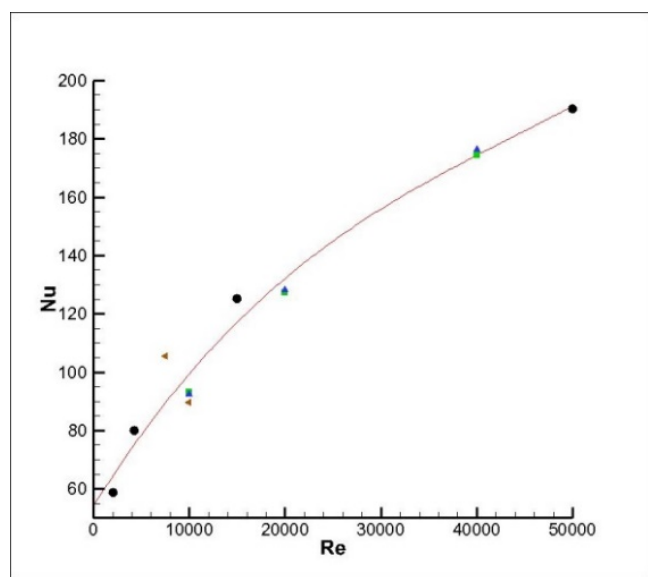

Fig.12 The distribution of average Nu under different Reynolds number 


\section{Analyze the impingement cooling on the wall under large heat flux}

Through the above analysis, this article selects the best cooling structure that the hole diameter is $\mathrm{d}=4 \mathrm{~mm}$, the impingement distance is $\mathrm{H}=4 \mathrm{~mm}$, hole spacing is $\mathrm{Xn}=\mathrm{Yn}=35.168 \mathrm{~mm}$, and the wall was heated by a constant heat flux $\mathrm{q}=500000 \mathrm{~W} / \mathrm{m}^{2}$ to simulate the heating of the combustion chamber wall. And numerical studies when the jet Reynolds number are $\operatorname{Re}=20000, \operatorname{Re}=30000$, $\operatorname{Re}=40000$ and $\operatorname{Re}=50000$.

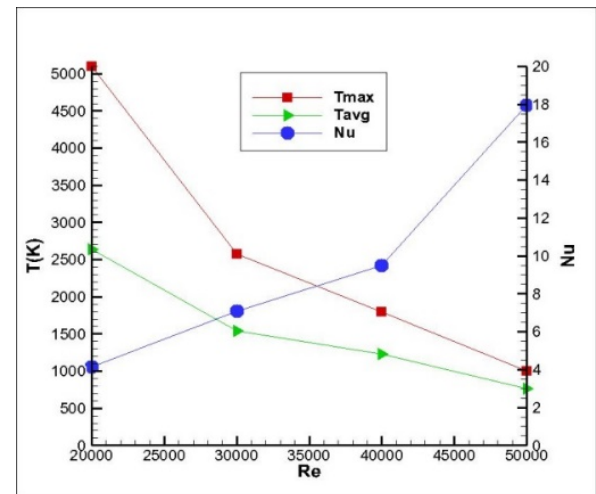

Fig.13 The distribution of wall temperature and Nu under different Reynolds numbers

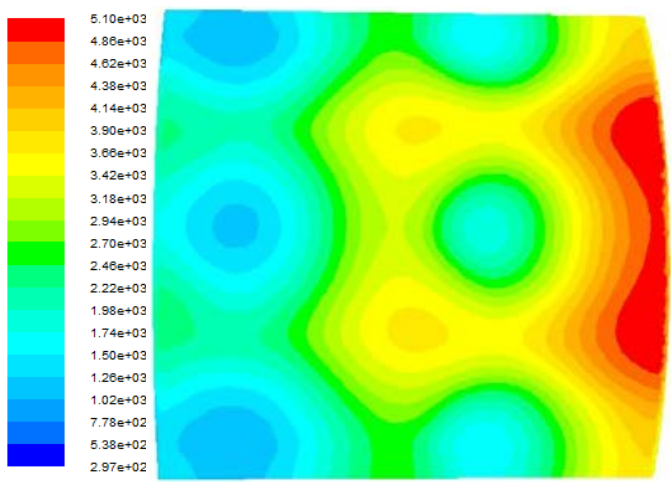

Fig.14 The wall temperature distribution at $\operatorname{Re}=20000$

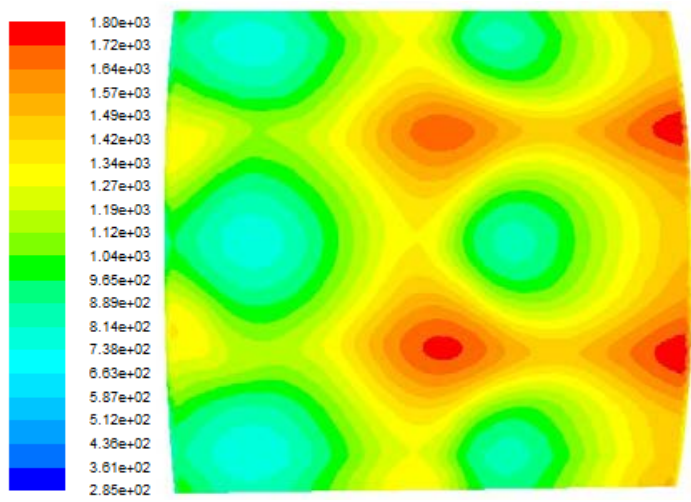

Fig.16 The wall temperature distribution at $\operatorname{Re}=40000$

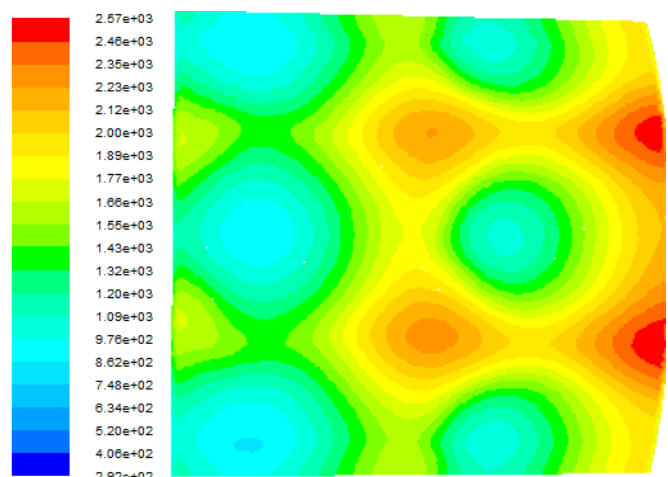

Fig.15 The wall temperature distribution at $\mathrm{Re}=30000$

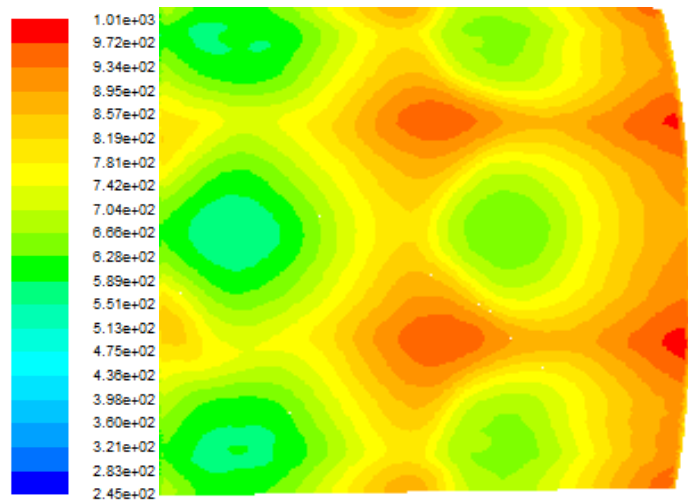

Fig.17 The wall temperature distribution at $\mathrm{Re}=50000$

Fig.13 is showing the maximum temperature, the average temperature and average $\mathrm{Nu}$ of the wall at different jet Reynolds numbers. Fig.14 to Fig.17 is temperature distributions diagram of wall at different jet Reynolds number. It can be seen from Fig. 13-Fig. 17 that under the small Reynolds number of jet, the maximum temperature of the wall is close to $5000 \mathrm{~K}$ and the average temperature is about $2636 \mathrm{~K}$, such high temperature can directly burn the wall. With the increase of jet Reynolds number, the maximum temperature and the average temperature of the wall have a significant decline, and the $\mathrm{Nu}$ increased. When the jet Reynolds number reaches 50000, the maximum wall temperature is close to $1000 \mathrm{~K}$, the average temperature is about $762 \mathrm{~K}$, and the wall temperature is within the range that the material can bear. It is calculated that when the Reynolds number of the jet is 50000, the air used for cooling accounts for about $30 \%$ of the total flow rate of the combustion 
chamber air, it is indicated that a better cooling structure can save the mass flow of cooling air.

\section{Conclusions}

This paper study respectively the influence on the characteristics of impingement cooling caused by the impingement hole diameter, jet Reynolds number, impingement distance, hole arrangement and hole spacing mainly through the numerical simulation method. And study the heat transfer of impingement cooling when the wall under large heat flux. Through the above analysis, under this paper's calculation conditions and parameters,we can get the main conclusions as follows:

(1) Within the range of the parameters that this paper was study, reducing the impact distance is beneficial to enhance the effect of impingement convective heat transfer. The arrangement of the holes has little effect on the cooling effect under different impact Reynolds number.

(2) Whether the arrangement is aligned or staggered, when impingement hole diameter is $4 \mathrm{~mm}$ to $8 \mathrm{~mm}$ and the hole spacing is $5.861 \mathrm{~mm}$ to $35.168 \mathrm{~mm}$ in the study scope, and increasing the Reynolds number can improve the heat transfer effect of target plate.

(3) It is found that under the same air mass flow rate, the cooling effect is the best when the impingement diameter is $\mathrm{d}=4 \mathrm{~mm}$, the impact distance is $\mathrm{H}=4 \mathrm{~mm}$, and the hole spacing is $\mathrm{Xn}=$ $\mathrm{Yn}=35.168 \mathrm{~mm}$.

(4) Numerical Investigation the impingement cooling on the wall under large heat flux by using the best cooling structure, it is found that When the jet Reynolds number reaches 50000, the maximum wall temperature is close to $1000 \mathrm{~K}$, the average temperature is about $762 \mathrm{~K}$, and the wall temperature is within the range that the material can bear.

\section{References}

[1] Wu Zhijuan. Investigation on the Cooling Characteristics of Combustion Chamber Flame Tube Wall [D], Nanjing: Nanjing University of Aeronautics and Astronautics, 2013.

[2] Arnab Roy, peter strakey, Todd Sidwell. Unsteady Heat Transfer Analysis to predict Combustor Wall Temperature in Rotating Detonation Engine[C]. AIAA-2015-51,2015.

[3] Steven Randall, Andrew St. George, Robert Driscoll, Vijay Anand, and, Ephraim J. Gutmark. Numerical and Experimental Study of Heat Transfer in a Rotating Detonation Engine[C]. AIAA-2015-53,2015.

[4] Andrew Naples. John Hoke. Rotating Detonation Engine Interaction with an Annular Ejector[C].AIAA-2014-52,2014.

[5] Andrew Naples. Matt Fotia. Design and Testing of a Rotating Detonation Engine for Open-Loop Gas Turbine Integration[C].ICDERS-2015-25,2015.

[6] Wang Lei, Zhang Jingzhou.Experimental study on heat transfer characteristics of jet array impinging [J]. Journal of Aerospace Power, 2009,24 (6) 1264-1269.

[7] Zhang Jingzhou, Li Yongkang, Tan Xiaoming,Li Liguo.Numerical computation and experimental investigation on local convective heat transfer characteristics for jet array impingement[J]. Journal of Aerospace Pow,2004,25(4):339-342.

[8] Wang Xingtao, Zhang Jingzhou, Tan Xiaoming.Numerical simulation on impingement cooling characteristics of pulsed detonation tube[J]. Journal of Aerospace Power,2011,26(11),2515-2521.

[9] Xie Hao, Zhang Jingzhou. Numerical study on heat transfer coefficient of jet array impingemeng [J].Energy Res and Utilization,2005(5):45-47. 
[10] Sun Runpeng, Zhu Weibing, Chen Changjiang, Chen Hong. Numerical investigation on heat transfer characteristics of jet array impingement cooling[J]. Journal of Thermal Science and Technology,2012,11(1):34-41.

[11] Chen Changjiang. Numerical Ivestigation on Flow and Heat Transfer Characteristics of Impingement Cooling[D].Harbin: Harbin Engineering University.

[12] Florschuetz L W,Metzger D E,Su C C.Heat transfer characteristics for jet array impingement with initial crossflow [C].ASME paper 83-GT-28 1983. 